\title{
Proposals for Antimicrobial Testing Guidelines Applied on Ajowan and Spanish Lavender Essential Oils"
}

\author{
Authors \\ Florence Souard 4,5 * \\ Affiliations \\ 1 Department of Research in Drug Development (RD3), \\ Pharmacognosy, Bioanalysis and Drug Discovery Unit, \\ Faculty of Pharmacy, Université libre de Bruxelles, Brussels, \\ Belgium \\ 2 Pranarôm International S. A. Ghislenghien, Belgium \\ 3 Unité de Recherche en Biotechnologie Végétale, Université \\ libre de Bruxelles, Gosselies, Belgium \\ 4 Department of Pharmacotherapy and Pharmaceutics \\ (DPP), Pharmacology, Pharmacotherapy and Pharmaceuti- \\ cal care Unit, Faculty of Pharmacy, Université libre de \\ Bruxelles (ULB), Brussels, Belgium \\ 5 Département de Pharmacochimie Moléculaire (DPM), \\ Université Grenoble Alpes, CNRS, Grenoble, France
}

Sofia Oliveira Ribeiro ${ }^{1}$, Stéphanie Fraselle ${ }^{1}$, Dominique Baudoux ${ }^{2}$, Abdesselam Zhiri ${ }^{2,3}$, Caroline Stévigny ${ }^{1 *}$,

Key words

antibacterial activity, broth dilution method, proposed guidelines, Lavandula stoechas, Trachyspermum ammi, Staphylococcus aureus

$\begin{array}{ll}\begin{array}{l}\text { received } \\ \text { accepted after revision } \\ \text { published online }\end{array} & \begin{array}{l}\text { November 19, } \\ \text { April 2, 202 } \\ \text { April 21, 2021 }\end{array} \\ \text { Bibliography } & \\ \text { Planta Med 2021; 87: 754-763 } & \\ \text { DOI } \quad 10.1055 / a-1475-0020 \\ \text { ISSN } \quad 0032-0943 \\ \text { C 2021. Thieme. All rights reserved. } \\ \text { Georg Thieme Verlag KG, Rüdigerstraße 14, } \\ \text { 70469 Stuttgart, Germany }\end{array}$

Correspondence

Oliveira Ribeiro Sofia (Ph. D. student/Researcher)

Department of Research in Drug Development (RD3),

Pharmacognosy, Bioanalysis, and Drug Discovery Unit,

Faculty of Pharmacy, Université libre de Bruxelles

Boulevard du Triomphe, 1050 Brussels, Belgium

Phone: + 32 (0) 26505298

sofia.marilia.oliveira.ribeiro@ulb.be

\section{ABSTRACT}

To fight the rising resistance of microorganisms to antibiotics, a strategy followed by several researchers is to focus on natural compounds, such as essential oils, as a source of potent antibacterial compounds. These last decades, hundreds of original papers have been written about microbiological assays that prove the antibacterial activity of essential oils and their use in the medical field. But can we really compare all the data available in the literature when the raw material, the microbiological assays, and/or the strains are different from one article to another? This review will point out the differences and the inadequate practices found in published articles that tested 2 lesser-studied essential oils-Spanish lavender and the ajowan-by the broth dilution method against Staphylococcus aureus, a human pathogenic bacterium. Many pitfalls were found in the literature, for example, a variable chemical composition rarely underlined by the authors, unidentified strains or clinical strains used without a related antibiogram, a lack of quality controls, and the assertion of questionable positive results. At last, some general guidelines that should be followed by every scientific researcher will be discussed.

\section{Introduction}

Today, there is significant concern about the rise of bacterial strain resistance. Governments and organizations have published several reports or global action plans to tackle this health problem [1-3]. One way of fighting the multidrug-resistant strains is to

\# Dedicated to Professor Arnold Vlietinck on the occasion of his 80th birthday. find new compounds with antibacterial activity. In the last 20 years, essential oils have been tested against different bacteria, and their antibacterial activity no longer needs to be proven [4$6]$. Using the terms "antibacterial" and "essential oil" on the database PubMed, we found no less than 2910 results for the period between 2000 and 2021 [7]. In the research articles, it is usual 
for the author to compare their results with the results obtained by other authors. However, can we truly compare results if the essential oils are chemically different, if the methods used have different parameters, and if the strains tested are different? Most scientists would say no, but that is what shows up in most of the literature available on this topic. The criticism of the testing and evaluation of the antibacterial activity of essential oils according to some methods is not new. In 1987, Janssen et al. [8] published a review where they analyzed 4 important aspects of the test methods: the assay technique, the growth medium, the microorganism, and the chemical composition of essential oil. More recently, Cos et al. [9] discussed recommendations for a "proof-ofconcept" for, among other things, the antibacterial activity of natural products. Specifically for the essential oils, Kalemba et al. [10] and Orchard et al. [11] have also pointed some variations in factors that can affect the results and make the comparison difficult: the chemical composition, the microbial strain collection number, the temperature and the length of incubation, the inoculum size, and the solubilizing solvent used. This review is an attempt to demonstrate briefly the variability and mistakes in some key factors when testing the antibacterial activity of essential oils by the broth dilution method. To contribute to the improvement of this method, some guidelines will be provided as a conclusion. The review will focus on the antimicrobial activity of 2 lesser-known essential oils-Lamiaceae, Lavandula stoechas L. (Spanish lavender) and the Apiaceae, Trachyspermum ammi (L.) Sprague (ajowan)tested by the broth dilution method against the human pathogenic strain Staphylococcus aureus.

\section{Experimental Research}

The search strategy for this review used the following limitation criteria: (I) the databases: SciFinder, ScienceDirect, Google Scholar, and PubMed; (II) the years of publication (from 2000 to 2020); (III) the selected languages (English, French, and Portuguese); (IV) the specific search terms: $X Y / X Y$ essential oil/X essential oil/Z essential oil/XY essential oil antibacterial/X essential oil antibacterial. Here $X Y$ must be replaced by the scientific name where $X$ is the genus and $Y$ is the specific name. The letter $Z$ refers to the English common name. The official synonyms for the 2 essential oils studied in this review, as listed on the website, "The Plant List" [12], were also searched in combination with the search terms mentioned above.

\section{The Broth Dilution Method and the Variability of Its Factors}

\section{Broth dilution method: brief description and variability of the inherent factors}

The 2 basic methods used to determine the antimicrobial activity of natural products are the diffusion and the dilution method. The first one is not described in this paper because we believe that this method is not appropriate for the complex volatile hydrophobic nature of the essential oils $[11,13]$. The low water solubility coefficient of the essential oil in the agar makes the inhibition zone incomparable with the results obtained by the dilution method [ 9 ,
13]. For example, Ghabraie et al. [14] used the 2 methods to test the antibacterial activity of several essential oils, and the activities against the same strain of $S$. aureus were different with each method. With the diffusion method $(4 \mu \mathrm{l}$ applied in a $6-\mathrm{mm}$ diameter cellulose test disc), ajowan was the most active (twice the inhibition zone of Chinese cinnamon), while in the dilution method, the Chinese cinnamon ( $\mathrm{MIC}=470 \mathrm{ppm}$ ) showed antibacterial activity at an MIC lower than the ajowan (MIC $=3750$ ppm). This is why we decided to focus on the dilution method, in which we always used a cosolvent (usually DMSO or Tween) to ensure the complete dissolution of the compounds contained in the essential oils. The importance of this cosolvent will be discussed later on.

The Clinical \& Laboratory Standards Institute (CLSI) provides universal guidelines to test products against different pathogens [15]. Briefly, for bacteria that grow aerobically such as S. aureus, the broth dilution method consists of a serial dilution of the essential oil on microplates (microdilution) or in tubes (macrodilution). The inoculum is then added, and, after an incubation period, the minimal inhibitory concentration (MIC) is determined. The MIC is determined by the naked eye and corresponds to the lowest well or tube where the bacteria growth is totally inhibited [16]. At this point, 3 factors can already be a source of variability: the medium, the inoculum, or the incubation period. Nevertheless, the CLSI standards precisely state the optimal procedure that they use for pure compounds: Mueller Hinton broth is the reference medium; the inoculum should be done by the suspension method with colonies less than 18-24 hold and with a final density of $5 \times 10^{5} \mathrm{CFU} /$ $\mathrm{mL}$; the tubes or the plates should be incubated at $35^{\circ} \mathrm{C} \pm 2{ }^{\circ} \mathrm{C}$ for 16-20 $\mathrm{h} \mathrm{[15].} \mathrm{The} \mathrm{same} \mathrm{parameters} \mathrm{are} \mathrm{also} \mathrm{recommended} \mathrm{by} \mathrm{the}$ European Committee on Antimicrobial Susceptibility Testing (EUCAST), which includes references to the International Standards Organization (ISO) recommendations [17]. These 3 parameters should not be open to variability, and the authors should be aware of these standards and apply them. The standardization of these parameters will not be discussed further in this paper.

Three major factors will be discussed in this paper: the chemical composition of the essential oil, the selected strains, and the controls to perform when testing essential oils by the broth dilution method. - Table 1 reviews all the variable components discussed above for L. stoechas L. and Trachyspermum ammi (L.) Sprague.

Variabilities on the chemical composition of essential oils

Many parameters can influence the variability of the chemical composition of essential oils, such as the genotype, the climate, seasonal variations, the soil composition, the plant organ, or the harvesting period [18]. Since 1968, the term chemotype has been used to characterize individuals morphologically identical but with a variation in the secondary metabolism. Due to all the abiotic and biotic factors that can influence the chemical profile of an essential oil, it is very difficult to identify and clearly describe a chemotype. Among the essential oils, despite the high chemical variability, not all of them are assigned by defined chemotypes $[19,20]$.

Three conditions having a major impact on the chemical composition of essential oils are the geographical plant origin, the organ, and the extractive method used. A good research practice 


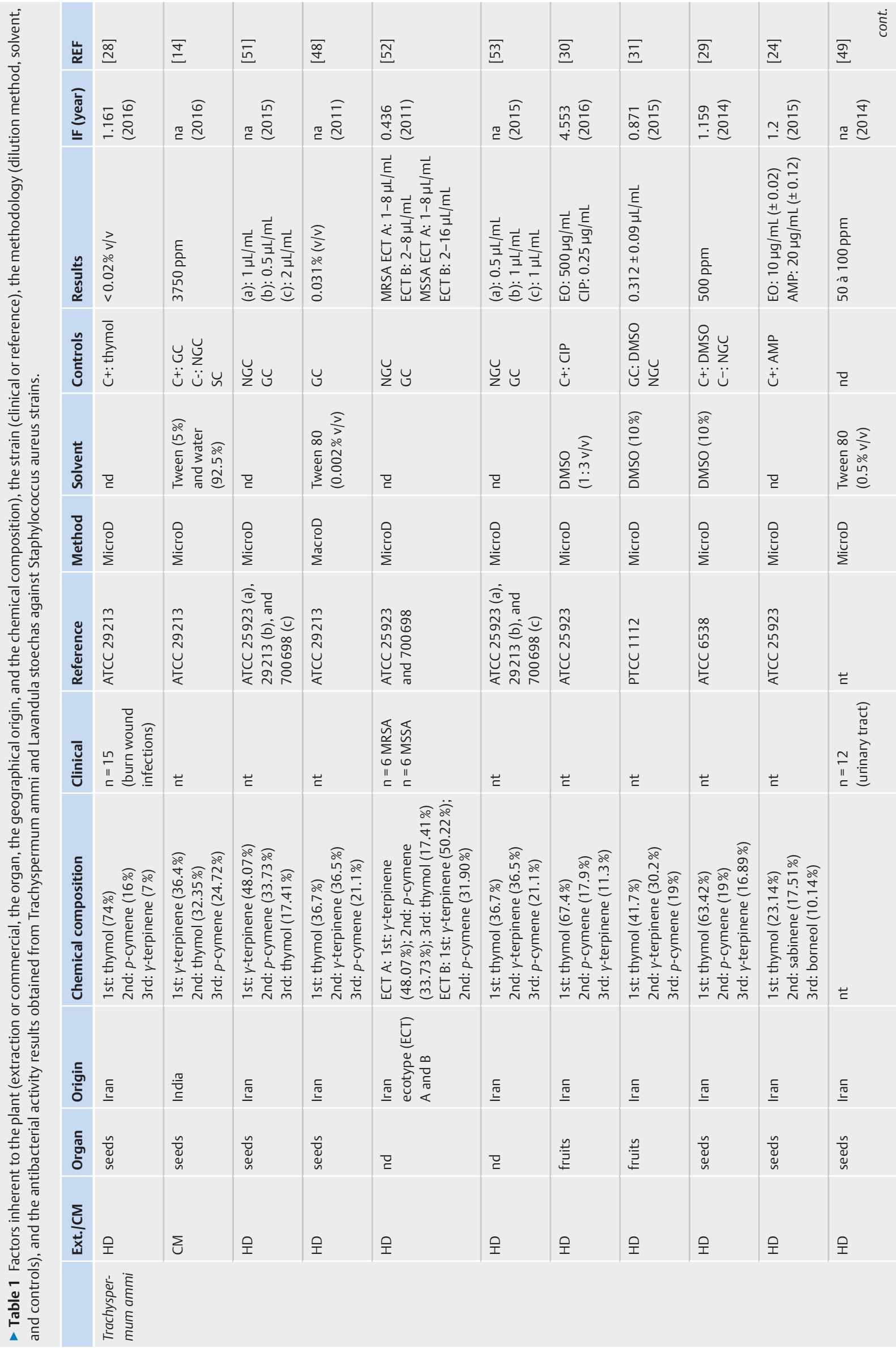




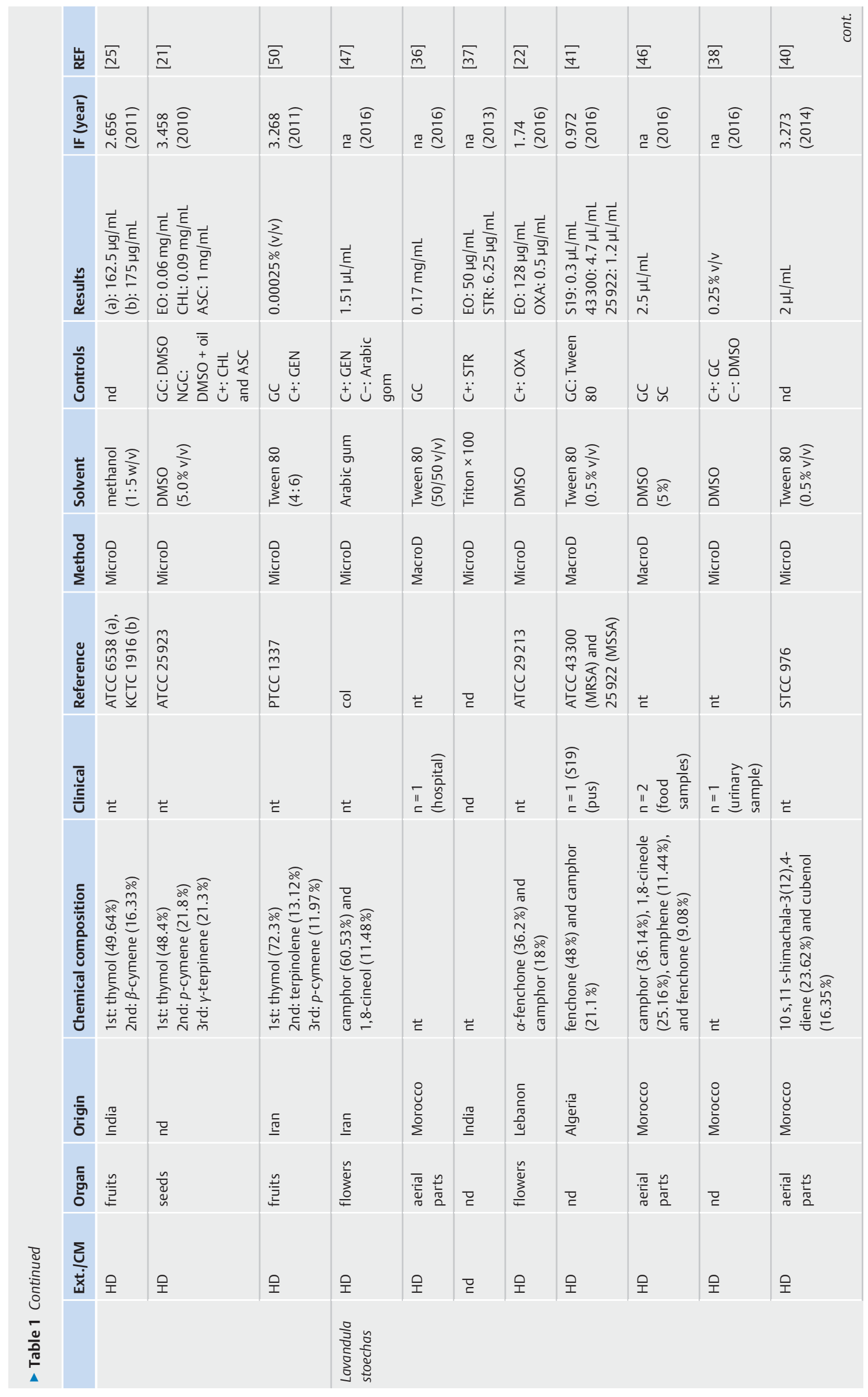




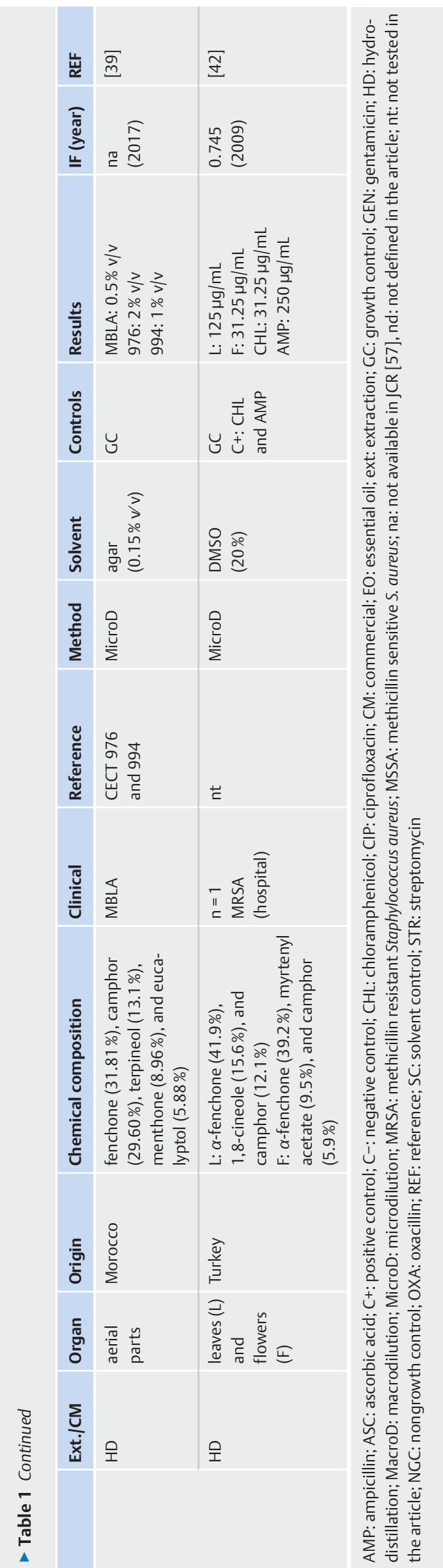

would be to always report at least these 3 parameters in all papers. In the first case, it is usual to record the country of origin, but some authors forget to indicate this information [21]. However, some authors, such as Khoury et al. [22], described perfectly the conditions of the harvested plant (region, district, GPS location, altitude, collection date, and voucher number). In their paper, the authors analyzed the antimicrobial activity of 11 Lamiaceae species harvested in Lebanon and looked at the chemical composition of the essential oil while also comparing it to other papers. Even when commercial extracts are used, the geographical origin and the used part should be mentioned. Ghabraie et al. [14] tested 32 commercial essential oils for their antibacterial activity, and they specified the origin, the distilled part, and the chemical composition. The correct botanical identification of the organ is also important. In the case of the ajowan, the fruit and the seed refers to the same organ, which is actually generalized as the fruit of T. ammi. In Table 1, the term used by the authors were maintained. Regarding the extraction method, an essential oil is defined by the European pharmacopeia as "Odorous product, usually of complex composition, obtained from a botanically defined plant raw material by steam distillation, dry distillation, or a suitable mechanical process without heating. Essential oils are usually separated from the aqueous phase by a physical process that does not significantly affect their composition" [23]. Then, the 3 methods are briefly described. As the extraction method can significantly change the chemical composition, it should always be done according to the European Pharmacopeia.

One of the most analytical techniques used to obtain the chemical content of essential oils is gas chromatography, which most of the time is coupled with a mass spectrometry detector [23]. The use of this analytical technique should be mandatory in all papers and should be correctly performed with a minimum of 3 separate injections. The use of a polar or apolar column should also be mentioned. The best approach would be to use both. Some manufacturers of commercial essential oil actually furnish the chemical analysis and the complete experimental conditions. This is why, even when a commercial essential oil is used, the chemical composition should be mentioned in the paper [14]. The usual major compounds of the essential oils are commonly known, so the best practices would be to test them all if they are commercially available. For example, Kazemi et al. [24] identified only $66.92 \%$ of all the compounds in T. ammi, but p-cymene which is known to be one of the major compounds (content of at least $16 \%)$, was surprisingly not in the list of the tested compounds. The accurate writing of the compounds is also important. Paul et al. [25] identified 2 major compounds, thymol and $\beta$-cymene, in the essential oil obtained after the hydrodistillation of the fruits of T. ammi harvested in India. According to PubChem [26], $\beta$-cymene is a synonym of $m$-cymene, a non-natural isomer of the $p$ cymene [27]. In this case, do Paul et al. [25] confuse $\beta$-cymene with the $p$-cymene? In their study, this compound ( $\beta$-cymene) is present at $16.33 \%$, a concentration similar to the ones reported by several authors for p-cymene in T. ammi [28-31]. Regarding the general composition, only Kazemi et al. [24] identified a completely different composition for T. ammi. In their study, the seeds were collected in Iran, and the essential oils were extracted by hydrodistillation according to the European pharmacopeia. In all the 
other papers, thymol and $y$-terpinene were reported mostly as the major compounds (results presented in $>$ Table 1 ). A second example is $L$. stoechas, an essential oil well-known for its variable chemical composition depending on many factors such as the geographic origin, the cultivars, and/or the environmental factors [32-35]. The data presented by some authors would be more interpretable if they had added the chemical composition [36-38].

\section{Variabilities and incomplete information about the strains}

In their review, Cos et al. [9] provide a recommended panel of microorganisms to be tested including Gram-positive and Gramnegative. Some authors only test their extracts on a single bacterium, which cannot be considered as a screening. The focus of this review is the comparison of results, and, to allow comparison, a standardized strain should always be tested [13]. How can we manage that when the strain is not issued from a reference collection and/or the number or the origin is not clearly specified? Indeed, some papers do not specify whether the tested $S$. aureus is a clinical or a reference strain [37,39], and sometimes the reference number of the strain is unclear. For example, Cherrat et al. [40] tested L. stoechas essential oil against 5 Gram-positive and 4 Gram-negative. Among the Gram-positive, they mentioned an STCC 976 from the Spanish Collection of Type Cultures. After a quick search, it appears that the correct reference for this strain is CECT 976. Bouyahya et al. [39] also used strains from the STCC to test the antibacterial activity of $L$. stoechas essential oil, but when checking the reference numbers for this review, it appears that S. aureus CECT 994 refers to Streptococcus uberis and not to an $S$. aureus strain.

Another problem is that the clinical strains are many times not described or characterized by an antibiogram, and comparison is difficult with such incomplete information. Also, if an antibiogram is performed, it should be mentioned in the paper. For example, before showing the MIC of the essential oil of $L$. stoechas, Chebaibi et al. [38] presented a table with the sensitivity of all the clinical strains towards a large panel of antibiotics. Hosseinkhani et al. [28] also performed an antibiogram on Mueller Hinton agar with 8 different classes of antibiotics for each clinical strain and classified them as multidrug-resistant when they were resistant to more than 3 different antibiotics classes. However, all the strains, including the reference ATCC strain, showed the same MIC $(<0.02 \mathrm{v} / \mathrm{v})$, which is very odd given the differences observed in the resistances. The authors did not comment on this unusual result [28]. Even in the case of a reference strain, it could be interesting to check if its resistance is within the ranges observed for a reported sensitive or resistant $S$. aureus. Sometimes mentioning the resistance of the strains (resistant [MRSA] or sensitive [MSSA] Staphylococcus aureus) without presenting the results could be acceptable. Bekka-Hadji et al. [41] did not present the results of an antibiogram but mentioned that the clinical strain used to test the essential oil of $L$. stoechas was identified by PCR as an MRSA, and they correctly used 2 reference strains (1 MRSA and 1 MSSA) as controls. Also in a study by Kirmizibekmez et al. [42], a clinical strain was used and defined as an MRSA, and indeed, when checked for this review, the 2 positive controls, chloramphenicol and ampicillin, were in the ranges of resistance according to the EUCAST breakpoints tables [43].

\section{Controls: unheeded and yet so important}

The EUCAST advises the use of a growth and nongrowth control as a basis. These controls are important to verify, respectively, if the strain is correctly growing and if the medium is sterile. Other controls are also required to establish a good interpretation of the results and guarantee a good analysis of the antibacterial activity.

Essential oils are highly hydrophobic and viscous. The use of a solubilizing agent is necessary to allow the distribution of all the oil in the medium. The most commonly used are Tween 80 and DMSO. The role of those emulsifying agents in the antibacterial activity of essential oil is not quite clear, especially for the Tweens $[10,44,45]$. Ideally, the solvent used to dilute the essential oils should be tested at the same concentrations alone against all the tested strains. This solvent control is important to check if it possesses any antibacterial activity (bacteriostatic or bactericidal) by itself at the tested concentration. Following this good practice, only some authors specified that the solvent control was performed $[14,46]$. Sadani et al. [47] tested their solvent control but used an unusual one, the Arabic gum. Unfortunately, most of the authors did not check the solvent antibacterial activity [22, 25, 30, $36,37,40,42,48-50]$ or if it was done, it was not mentioned. In other cases, the use of a solvent is not mentioned at all [24, 28, 51-53].

Another important control that should always be done is a positive control, with either an antibiotic or a compound known to be active against the selected strain. For example, Hosseinkhani et al. [28] used thymol as a positive control, but unfortunately, the results of its MIC against the tested strains are not mentioned. This is also the case of other authors $[47,50]$. In our point of view, readers have to be informed of all mentioned data. An antibiotic can also be tested as a positive control. Very few authors performed such positive control and presented the results $[21,22$, 24, 30, 37, 42].

Some authors also mix the controls. The growth control is often confused with the solvent control $[21,31,41]$ or with the positive control $[14,38]$. The nongrowth control should not be called a negative control $[14,29]$ since, by definition, a negative control is the use of a compound without activity. Chebaibi et al. [38] and Sadani et al. [47] wrongly described the solvent control as a negative control while Gandomi et al. [29] also wrongly described it as a positive control, to our point of view.

Disparity in the results and importance of all the mentioned factors

The numerical data of the results presented in $>$ Table $\mathbf{1}$ were kept in their original form. However, it would be appropriate to use uniform units of concentration. EUCAST favors the expression of MIC by $\mathrm{mg} / \mathrm{L}$ or $\mu \mathrm{g} / \mathrm{mL}$ [17]. The results of antibiotics breakpoints presented by the CLSI standards are also expressed in $\mu \mathrm{g} /$ $\mathrm{mL}$ [54]. Why complicate the comparison of results by expressing them in non-recommended units? As we can see in > Table 1, most of the authors do not follow or are not aware of those recommendation and expressed their results in \% v/v [28, 38, 39, 48, 50], ppm [14,29,49], $\mu \mathrm{l} / \mathrm{mL}[31,40,41,46,47,51-53]$, or less confusing, in $\mathrm{mg} / \mathrm{mL}[21,36]$. In the following discussion, the results were converted to $\mu \mathrm{g} / \mathrm{mL}$ to allow comparisons and better comprehension. 
Some examples presented in $>$ Table $\mathbf{1}$, in which the same plant and strain were tested, are key examples of the importance of a correct description and careful use of the factors mentioned before.

Five authors tested the essential oil of $T$. ammi against the reference strain ATCC 29213 [14,28,48,51,53]. This provides a good example of how results are sometimes not comparable. They used the same strain but the observed MIC varied from less than $20 \mu \mathrm{g} / \mathrm{mL}$ up to $3750 \mu \mathrm{g} / \mathrm{mL}$. What could explain such variability? Hosseinkhani et al. [28] did not mention if a solvent was used, but the fact that an MIC $<20 \mu \mathrm{g} / \mathrm{mL}$ was found can arise from the chemical composition of the essential oil, which is composed of $74 \%$ of thymol. This compound is known for its antibacterial activity [55]. Oppositely, Moein et al. [51] tested an essential oil with a very low amount of thymol (17.41\%) but high $\gamma$-terpinene $(48.07 \%)$ and observed an MIC of $500 \mu \mathrm{g} / \mathrm{mL}$. The least antibacterial activity was found by Ghabraie et al. [14] with an MIC of $3750 \mu \mathrm{g} / \mathrm{mL}$. However, Goudarzi et al. [48] tested an essential oil with comparable chemical composition as the one tested by Ghabraie et al. [14] and found an MIC of $31 \mu \mathrm{g} / \mathrm{mL}$. Analyzing all the factors, the differences between the 2 papers are the geographical plant origin and the Tween 80 amount used to dilute the essential oil: India and 5\% [14] versus Iran and 0.002\% [48], respectively. As mentioned before, the impact of the Tweens is not known, but the minor compounds due to the different geographical origin can impact the antibacterial activity. Different authors mentioned the possible synergy between several compounds in an essential oil, including the minor ones [56]. Cos et al. [9] stipulated that an extract should only be considered active when the concentration is below $100 \mu \mathrm{g} / \mathrm{mL}$. In this case, only Hosseinkhani et al. [28] and Goudarzi et al. [48] presented exploitable results.

In 2011, Goudarzi et al. [48] published a study where the seeds of ajowan were described to have a MIC of $31 \mu \mathrm{g} / \mathrm{mL}$ against the strain S. aureus ATCC 29213. Later on, in 2015, Zomorodian et al. [53] who is also co-author of Goudarzi et al. [48], published results where the same strain was used and with an essential oil of ajowan of the same composition regarding the major compounds. He did not specify the part of the plant or if a cosolvent was used for MIC measurements, but he described a MIC of $1000 \mu \mathrm{g} / \mathrm{mL}$. The difference in the obtained results can arise from different parameters in the microbiologic methods chosen by the authors: the use of a different cosolvent or/and the different chemical composition due, for example, to inappropriate storage conditions (if the same was used?), etc. At last, we can only make suppositions since Zomorodian et al. [53] did not mention the previous study of Goudarzi et al. [48] and there was no extensive description on the second work.

The chemical composition is highly variable in essential oils, and because $L$. stoechas does not have defined chemotypes, its variability is indubitable. Just by looking at the results presented in $>$ Table 1, 5 different chemical profiles can be identified: (I) high camphor (60.53\%) and no fenchone [47]; (II) camphor and 1,8-cineole as major compounds with low fenchone (9.08\%) [46]; (III) the type fenchone-camphor [22, 39,41]; (IV) fenchone as major compounds with low camphor [42]; (V) and an unusual profile with no camphor and no fenchone [40]. This demonstrates the importance of analyzing the chemical composition. Regarding the results and according to the active threshold mentioned by Cos et al. [9] all the samples, independent of the chemical profile, are not active. The best MICs were obtained by Khoury et al. [22] with the type fenchone-camphor against a reference strain sensitive to oxacillin $(128 \mu \mathrm{g} / \mathrm{ml})$ and by Kirmizibekmez et al. [42] with the high fenchone and low camphor type against an MRSA clinical strain $(125 \mu \mathrm{g} / \mathrm{ml})$. With other clinical strains, Bekka-Hadji et al. [41] found a MIC of $300 \mu \mathrm{g} / \mathrm{ml}$, close to the one found by Chebaibi et al. [38] $(250 \mu \mathrm{g} / \mathrm{ml})$. Despite the use of different strains, these comparisons are possible because Khoury et al. [22] correctly specified the number of the reference strain and the other authors presented the results of the characterization of their clinical strains. The same is not possible with the results of Bachiri et al. [36] and Gayatri et al. [37] who presented neither the chemical composition nor the sensibility of the used strains.

As shown, all the factors to record are important to allow a correct interpretation and perform comparisons of the results between studies. If we want to compare the quality of the articles according to an objective criterion, we can look at the Impact Factor (IF) of the journal at the year of publication. In $>$ Table 1 , in the last column, the IF of each article at the published year is indicated (only the IF registered at the Journal of Citations Reports [JCR] [57] were considered). Among the 24 referred articles, only 9 have an IF above 1, and 11 articles have no IF available on the JCR. The highest IF is 4.6 and the lowest is 0.4 . Comparing the flaws in the previously mentioned practices and the IF of the articles, there is no evident correlation. Even in journals with an IF above 2, there are mistakes that slipped through the cracks, and, on the contrary, articles that are almost complete can be found in journals with a low or non-existent IF. At last, it will essentially depend on the authors and reviewers to check if all the parameters are present and good practices have been followed to allow a good interpretation of the data.

\section{Conclusions}

The literature concerning the antibacterial activity of essential oils is very difficult to interpret. Besides the high variable chemical composition of the essential oils that are sensitive to many factors, intrinsic and/or extrinsic, the method used to test their antibacterial activity is also open to variation in the selected method, the tested strains and the controls. In this review, the literature regarding the antibacterial activity of $L$. stoechas and $T$. ammi against the Gram-positive $S$. aureus by the microdilution method was analyzed. All these articles presented more or less important omissions to prevent an appropriate interpretation of their results. Without the chemical composition of the tested essential oil or an indication of the resistance of the strain, the results are pointless. Even when this important information is mentioned, essential oils having a similar chemical profile can present varying MICs. This may occur from the variable parameters of the method used. To prevent the risk of misinterpretation, whatever method is used, every author should follow some essential guidelines/recommendations:

- All parameters that may affect the experimental assay should be strictly defined in the article. 
- The rules defined by entities such as CLSI and EUCAST for the medium, inoculum, and incubation period should be followed.

- The information about the plant should be correctly described, such as the geographical origin of the plant, the organ used, and the extraction method. Even in the case of commercial essential oil, this data should be included.

- The chemical composition of the essential oil should be characterized and compared with the literature.

- When using a reference strain, its identification number should be well specified.

- When using a clinical strain, the origin of the sample should be described, and its resistance to a large panel of antibiotics or at least the antibiotics used in the study should be characterized.

- When using the broth dilution method, at least 2 essential controls are needed: the growth and nongrowth control to check, respectively, the strain viability and the medium sterility.

- As the essential oil is diluted in a solvent, it should be tested alone at the same concentration against all the strains to at least confirm that it is not antibacterial by itself.

- A positive control, preferably using different classes of antibiotics, should also be performed in the case of a reference strain, but especially in the case of a clinical one, to confirm the sensitivity or resistance.

- At last, all the MIC should be expressed in $\mathrm{mg} / \mathrm{L}$ or $\mu \mathrm{g} / \mathrm{mL}$ to achieve homogenization of the results available in the literature.

Those recommendations are applicable for all the essential oils and other kinds of assays, specifically regarding the composition, the numbers, and the resistance of the strains. These are simple steps and procedures that the entire scientific community should take into account when testing essential oil, including the authors and the reviewers.

\section{Contributors' Statement}

Conceptualization: S. Oliveira Ribeiro, C. Stévigny and F. Souard; data curation: S. Oliveira Ribeiro and F. Souard; funding acquisition: D. Baudoux and A. Zhiri; methodology: S. Oliveira Ribeiro; project administration: D. Baudoux, A. Zhiri and C. Stévigny; resources: D. Baudoux, A. Zhiri and C. Stévigny; supervision: C. Stévigny and F. Souard; writing - original draft: S. Oliveira Ribeiro; critical revision of the manuscript: S. Fraselle, C. Stévigny and F. Souard. English revision: S. Fraselle; writing - review and editing: S. Oliveira Ribeiro, S. Fraselle, D. Baudoux, A. Zhiri, C. Stévigny and F. Souard.

\section{Acknowledgements}

The financial support of the Université libre de Bruxelles (Brussels, Belgium) and Pranarôm International S.A (Ghislenghien, Belgium) are gratefully acknowledged.

\section{Conflict of Interest}

The authors declare that they have no conflict of interest.

\section{References}

[1] O'Neill J. Tackling drug-resistant infections globally: Final report and recommendations. 2016. Accessed April 16, 2021 at: http://amr-review. org/

[2] WHO. Global Antimicrobial Resistance Surveillance System (GLASS) Report: Early Implementation 2017-2018. Geneva: WHO; 2018

[3] EUCAST. Surveillance of antimicrobial resistance in Europe 2018. Stockholm: ECDC; 2019. Accessed November 22, 2019 at: https://www.ecdc. europa.eu/en/publications-data/surveillance-antimicrobial-resistanceeurope-2018

[4] Tariq S, Wani S, Rasool W, Shafi K, Bhat MA, Prabhakar A, Shalla AH, Rather MA. A comprehensive review of the antibacterial, antifungal and antiviral potential of essential oils and their chemical constituents against drug-resistant microbial pathogens. Microb Pathog 2019; 134: 103580. doi:10.1016/j.micpath.2019.103580

[5] Mehdizadeh L, Moghaddam M. Essential Oils: biological Activity and therapeutic Potential. In: Grumezescu AM, Holban AM, eds. Therapeutic, probiotic, and unconventional Foods. London: Elsevier Academic Press; 2018: 167-179

[6] Yu Z, Tang J, Khare T, Kumar V. The alarming antimicrobial resistance in ESKAPEE pathogens: Can essential oils come to the rescue? Fitoterapia 2020; 140: 104433. doi:10.1016/j.fitote.2019.104433

[7] PubMed. Accessed March 1, 2021 at: https://pubmed.ncbi.nlm.nih.gov/ ?term=antibacterial+essential+oil

[8] Janssen AM, Scheffer JJ, Baerheim Svendsen A. Antimicrobial activity of essential oils: a 1976-1986 literature review. Aspects of the test methods. Planta Med 1987; 53: 395-398. doi:10.1055/s-2006-962755

[9] Cos P, Vlietinck AJ, Berghe DV, Maes L. Anti-infective potential of natural products: How to develop a stronger in vitro 'proof-of-concept'. J Ethnopharmacol 2006; 106: 290-302. doi:10.1016/j.jep.2006.04.003

[10] Kalemba D, Kunicka A. Antibacterial and antifungal properties of essential oils. Curr Med Chem 2003; 10: 813-829. doi:10.2174/ 0929867033457719

[11] Orchard A, van Vuuren S. Commercial essential oils as potential antimicrobials to treat skin diseases. Evid Based Complement Alternat Med 2017; 2017: 4517971. doi:10.1155/2017/4517971

[12] The plant list. Version 1.1. 2013. Accessed August 27, 2020 at: http:/ www.theplantlist.org/

[13] Eloff JN. Avoiding pitfalls in determining antimicrobial activity of plant extracts and publishing the results. BMC Complement Altern Med 2019; 19: 106. doi:10.1186/s12906-019-2519-3

[14] Ghabraie M, Vu KV, Tata L, Salmieri S, Lacroix M. Antimicrobial effect of essential oils in combinations against five bacteria and their effect on sensorial quality of ground meat. LWT-Food Sci Technol 2016; 66: 332339. doi:10.1016/j.lwt.2015.10.055

[15] CLSI. Microbiology and Antimicrobial Susceptibility Testing (AST) standards and guidelines on test methods and QC procedures. Wayne, PA, USA: Clinical and Laboratory Standards Institute; 2020

[16] CLSI. Methods for dilution antimicrobial susceptibility tests for bacteria that grow aerobically. Approved standard, Tenth Edition. 10e éd. Vol. M07-A10. Wayne, PA, USA: Clinical and Laboratory Standards Institute; 2015

[17] EUCAST. EUCAST reading guide for broth microdilution version 2.0 . 2020. Accessed March 28, 2020 at: https://www.eucast.org

[18] Properzi A, Angelini P, Bertuzzi G, Venanzoni R. Some biological activities of essential oils. Med Aromat Plants 2013; 2: 136-140. doi:10.4172/ 2167-0412.1000136

[19] Polatoglu K. "Chemotypes" - A Fact that should not be ignored in natural product studies. Nat Prod | 2013; 3: 10-14. doi:10.2174/ 2210315511303010004 
[20] Trindade H, Pedro LG, Figueiredo AC, Barroso JG. Chemotypes and terpene synthase genes in Thymus genus: state of the art. Ind Crops Prod 2018; 124: 530-547. doi:10.1016/j.indcrop.2018.08.021

[21] Oroojalian F, Kasra-Kermanshahi R, Azizi M, Bassami MR. Phytochemical composition of the essential oils from three Apiaceae species and their antibacterial effects on food-borne pathogens. Food Chem 2010; 120 : 765-770. doi:10.1016/j.foodchem.2009.11.008

[22] Khoury M, Stien D, Eparvier V, Ouaini N, El Beyrouthy M. Report on the medicinal use of eleven Lamiaceae species in Lebanon and rationalization of their antimicrobial potential by examination of the chemical composition and antimicrobial activity of their essential oils. Evid Based Complement Alternat Med 2016; 17: 2547169. doi:10.1155/ 2016/2547169

[23] EDQM Council of Europe. Ph. Eur. Essential oils. In: European Pharmacopeia (Ph. Eur.). Strasbourg, France: EDQM; 2021: 864-865

[24] Kazemi M. Chemical composition and antimicrobial, antioxidant activities and anti-inflammatory potential of Achillea millefolium L., Anethum graveolens L., and Carum copticum L. essential oils. J Herb Med 2015; 5: 217-222. doi:10.1016/j.hermed.2015.09.001

[25] Paul S, Dubey RC, Maheswari DK, Kang SC. Trachyspermum ammi (L.) fruit essential oil influencing on membrane permeability and surface characteristics in inhibiting food-borne pathogens. Food Control 2011; 22: 725-731. doi:10.1016/j.foodcont.2010.11.003

[26] National Center for Biotechnology Information. PubChem Compound Summary for CID 10812, M-Cymene. Accessed August 19, 2020 at: https://pubchem.ncbi.nlm.nih.gov/compound/M-Cymene

[27] Marchese A, Arciola CR, Barbieri R, Nabavi SF, Tsetegho Sokeng AJ, Izadi M, Jafari NJ, Suntar I, Daglia M, Nabavi SM. Update on monoterpenes as antimicrobial agents: A particular focus on p-cymene. Materials (Basel) 2017; 10: 947. doi:10.3390/ma10080947

[28] Hosseinkhani F, Jabalameli F, Banar M, Abdellahi N, Taherikalani M, Leeuwen WB, Emaneini M. Monoterpene isolated from the essential oil of Trachyspermum ammi is cytotoxic to multidrug-resistant Pseudomonas aeruginosa and Staphylococcus aureus strains. Rev Soc Bras Med Trop 2016; 49: 172-176. doi:10.1590/0037-8682-0329-2015

[29] Gandomi H, Abbaszadeh S, Jebellijavan A, Sharifzadeh A. Chemical constituents, antimicrobial and antioxidative effects of Trachyspermum Ammi essential oil. J Food Process Preserv 2014; 38: 1690-1695. doi:10.1111/jfpp.12131

[30] Vitali LA, Beghelli D, Nya PCB, Bistoni O, Cappellacci L, Damiano S, Lupidi G, Maggi F, Orsomando G, Papa F, Petrelli D, Petrelli R, Quassinti L, Sorci L, Zadeh MM, Bramucci M. Diverse biological effects of the essential oil from Iranian Trachyspermum ammi. Arab J Chem 2016; 9: 775-786. doi:10.1016/j.arabjc.2015.06.002

[31] Moosavi-Nasab M, Saharkhiz M, Ziaee E, Moayedi F, Koshani R, Azizi R. Chemical compositions and antibacterial activities of five selected aromatic plants essential oils against food-borne pathogens and spoilage bacteria. J Essent Oil Res 2015; 28: 241-251. doi:10.1080/ 10412905.2015.1119762

[32] Insawang S, Pripdeevech P, Tanapichatsakul C, Khruengsai S, Monggoot S, Nakham T, Artrod A, D'Souza PE, Panuwet P. Essential oil compositions and antibacterial and antioxidant activities of five Lavandula stoechas cultivars grown in Thailand. Chem Biodivers 2019; 16: e1900371. doi:10.1002/cbdv.201900371

[33] Carrasco A, Ortiz-Ruiz V, Martinez-Gutierrez R, Tomas V, Tudela J. Lavandula stoechas essential oil from Spain: Aromatic profile determined by gas chromatography-mass spectrometry, antioxidant and lipoxygenase inhibitory bioactivities. Ind Crops Prod 2015; 73: 16-27. doi:10.1016/j. indcrop.2015.03.088

[34] Raina A, Negi K. Comparative essential oil composition of Lavendula species from India. J Herbs Spices Med Plants 2012; 18: 268-273. doi:10.1080/10496475.2012.690142

[35] Angioni A, Barra A, Coroneo V, Dessi S, Cabras P. Chemical composition, seasonal variability, and antifungal activity of Lavandula stoechas L. ssp. stoechas essential oils from stem/leaves and flowers. J Agric Food Chem 2006; 54: 4364-4370. doi:10.1021/jf0603329

[36] Bachiri L, Echchegadda G, Ibijbijen J, Nassiri L. Etude phytochimique et activité antibactérienne de deux espèces de lavande autochtones au Maroc: "Lavandula stoechas L. et Lavandula dentata L.» Eur J Sci Res 2016; 12: 313-333. doi:10.19044/esj.2016.v12n30p313

[37] Gayatri MC, Sudha U, Shubha J, Kavya K. Evaluation of antibacterial activity of Lavandula stoechas L. essential oil. J Spices Aromat Crops 2013; 22: 188-193

[38] Chebaibi A, Marouf Z, Rhazi-Filali F, Fahim M, Ed-Dra A. Évaluation du pouvoir antimicrobien des huiles essentielles de sept plantes médicinales récoltées au Maroc. Phytothérapie 2016; 14: 355-362. doi:10.1007/s10298-015-0996-1

[39] Bouyahya A, Et-Touys A, Abrini ], Talbaoui A, Fellah H, Bakri Y, Dakka N. Lavandula stoechas essential oil from Morocco as novel source of antileishmanial, antibacterial and antioxidant activities. Biocatal Agric Biotechnol 2017; 12: 179-184. doi:10.1016/j.bcab.2017.10.003

[40] Cherrat L, Espina L, Bakkali M, Pagán R, Laglaoui A. Chemical composition, antioxidant and antimicrobial properties of Mentha pulegium, Lavandula stoechas and Satureja calamintha Scheele essential oils and an evaluation of their bactericidal effect in combined processes. Innov Food Sci Emerg Technol 2014; 22: 221-229. doi:10.1016/j.ifset.2013.12.016

[41] Bekka-Hadji F, Bombarda I, Touati A. Antibacterial activity against methicillin-resistant Staphylococcus aureus of five essential oils from Algerian medicinal plants (Lamiaceae). J Essent Oil Res 2016; 28: 518-527. doi:10.1080/10412905.2016.1161564

[42] Kirmizibekmez H, Demirci B, Yeşilada E, Başer KHC, Demirci F. Chemical composition and antimicrobial activity of the essential oils of Lavandula stoechas L. ssp. stoechas growing wild in Turkey. Nat Prod Commun 2009; 4: 1001-1006

[43] EUCAST - The European Committee on Antimicrobial Susceptibility Testing. Breakpoint tables for interpretation of MICs and zone diameters. Version 10.0. 2020. Accessed April 16, 2021 at: http://www. eucast.org

[44] Ma Q, Davidson PM, Zhong Q. Antimicrobial properties of microemulsions formulated with essential oils, soybean oil, and Tween 80 . Int J Food Microbiol 2016; 226: 20-25. doi:10.1016/j.ijfoodmicro.2016. 03.011

[45] Kaur G, Mehta SK. Developments of Polysorbate (Tween) based microemulsions: Preclinical drug delivery, toxicity and antimicrobial applications. Int J Pharm 2017; 529: 134-160. doi:10.1016/j.ijpharm.2017. 06.059

[46] Ez Zoubi Y, El-Akhal F, Berrada S, Maniar S, Bekkari H, Lalami AEO. Struggle against bacterial diseases: chemical composition and antimicrobial activity of the essential oil of Lavandula stoechas L. from Morocco. Int J Pharm Sci Rev Res 2016; 36: 99-104

[47] Sadani S, Shakeri A. Antimicrobial activity of the essential oils of Lavandula stoechas flowers extracted by microwave. J Med Plants Stud 2016; 4: 224-228

[48] Goudarzi GR, Saharkhiz M, Sattari M, Zomorodian K. Antibacterial activity and chemical composition of ajowan (Carum copticum Benth. \& Hook) essential oil. J Agric Sci Technol 2011; 13: 203-208

[49] Hassanshahian M, Bayat Z, Saeidi S, Shiri Y. Antimicrobial activity of Trachyspermum ammi essential oil against human bacterial. Int J Adv Biol Biomed Res 2014; 2: 18-24

[50] Oskuee RK, Behravan J, Ramezani M. Chemical composition, antimicrobial activity and antiviral activity of essential oil of Carum copticum from Iran. Avicenna J Phytomedicine 2011; 1: 83-90. doi:10.22038/ajp. 2011.126

[51] Moein M, Zomorodian K, Pakshir K, Yavari F, Motamedi M, Zarshenas M. Trachyspermum ammi (L.) sprague: chemical composition of essential oil and antimicrobial activities of respective fractions. J Evid-Based Complement Altern Med 2015; 20: 50-56. doi:10.1177/2156587214553302 
[52] Zomorodian K, Moein MR, Rahimi M], Pakshir K, Ghasemi Y, Abedi S, Sharbatfar S. Possible application and chemical compositions of carum copticum essential oils against food borne and nosocomial pathogens. Middle-East J Sci Res 2011; 9: 239-245

[53] Zomorodian K, Ghadiri P, Saharkhiz M], Moein MR, Mehriar P, Bahrani F, Golzar T, Pakshir K, Fani MM. Antimicrobial activity of seven essential oils from Iranian aromatic plants against common causes of oral infections. Jundishapur J Microbiol 2015; 8: e17766. doi:10.5812/jjm.17766

[54] CLSI. Performance Standards for antimicrobial Susceptibility Testing; Twenty-Fifth informational Supplement. 25e ed. Vol. M100-S25. Wayne, PA, USA: Clinical and Laboratory Standards Institute; 2015
[55] Marchese A, Orhan IE, Daglia M, Barbieri R, Di Lorenzo A, Nabavi SF, Gortzi O, Izadi M, Nabavi SM. Antibacterial and antifungal activities of thymol: a brief review of the literature. Food Chem 2016; 210: 402414. doi:10.1016/j.foodchem.2016.04.111

[56] Padalia H, Moteriya P, Baravalia Y, Chanda S. Antimicrobial and synergistic Effects of some essential Oils to fight against microbial Pathogens a Review. In: Méndez-Vilas A, ed. The Battle against microbial Pathogens: basic Science, technological Advances and educational Programs. Badajoz, Spain: Formatex Research Center; 2015: 34-45

[57] Journal Impact Factor. Journal Citation Reports (Clarivate Analytics, 2020). Accessed August 17, 2020 at: https://clarivate.com/webofsciencegroup/ solutions/journal-citation-reports/ 